\title{
ANÁLISE DE PARÂMETROS DE PROCESSO RELACIONADOS AO CRESCIMENTO DE Aspergillus oryzae EM BIORREATORES DE AGITAÇÃO MECÂNICA E AIRLIFT
}

\author{
F. H. STUANI ${ }^{1}$, G. PAGANIN ${ }^{1}$, L. MENEGHEL ${ }^{1}$, E. MALVESSI ${ }^{1}$, M. M. SILVEIRA $^{1}$ \\ ${ }^{1}$ Universidade de Caxias do Sul, Instituto de Biotecnologia, Laboratório de Bioprocessos \\ E-mail para contato: fhstuani@ucs.br
}

\begin{abstract}
RESUMO - O suprimento e a demanda de oxigênio, necessários para o controle do processo de transferência de massa gás-líquido, são grandezas de transformação fundamentais a serem analisadas em cultivos fúngicos, em razão do metabolismo unicamente aeróbio destes microrganismos. Neste trabalho foram avaliadas distintas configurações de impelidores (Rushton e pitched blade) e aeradores (pedra de vidro sinterizado e ferradura) no crescimento de Aspergillus oryzae, em biorreatores de agitação mecânica e airlift. Dentre os principais resultados, independentemente da configuração analisada, valor superior de concentração de biomassa foi obtido em biorreator de agitação mecânica $(6,34 \mathrm{~g} / \mathrm{L})$, em menor tempo de cultivo $(24 \mathrm{~h})$, podendo estar relacionado ao tipo de impelidor utilizado (Rushton) e às correntes de fluxo radiais, auxiliando na obtenção de biomassa. A maior velocidade específica de consumo de substrato $\left(0,75 \mathrm{~h}^{-1}\right)$, entretanto, foi determinada em biorreator airlift, indicando uma adequada oxigenação do meio com o tipo de aerador (vidro sinterizado) utilizado. Os dados mostram a influência tanto do tipo de aspersor e do tamanho das bolhas geradas como dos impelidores e das correntes de fluxo sobre a transferência de massa gás-líquido em cultivos fúngicos.
\end{abstract}

\section{INTRODUÇÃO}

O conhecimento da engenharia bioquímica está intimamente relacionado com os processos biotecnológicos. Dentre eles, podem-se destacar aqueles que visam à produção de enzimas microbianas utilizando linhagens fúngicas de Aspergillus (Jayani et al., 2005; Rezazadeh Bari et al., 2010; Gómez Sánchez et al., 2012). Estudos relacionados à geometria do reator, utilização de impelidores e de aspersores de gás que auxiliam na transferência de massa, bem como a análise das particularidades do processo, como a sensibilidade fúngica ao cisalhamento provocado pela agitação, são de primordial importância para a produção de pectinases (Fontana et al., 2009; Scargiali et al, 2014).

Dentre os principais equipamentos empregados para a obtenção de produtos microbianos, têm-se os biorreatores com agitação mecânica, com agitadores acoplados ao eixo central para realizar a agitação e a mistura, e os reatores com agitação pneumática (airlift), tendo uma região aspergida com gás e de menor densidade de fluido (riser) e uma região sem gás e maior densidade (downcomer), responsáveis pela circulação do fluido (Najafpour, 2007).

O suprimento e a demanda de oxigênio são grandezas comumente analisadas em cultivos 
microbianos. Os fungos, microrganismos usualmente empregados na produção de pectinases, dependem de um sistema com fornecimento de oxigênio. Como consequência do crescimento das hifas em aglomerados, ocorrem alterações reológicas e diminuição da transferência de oxigênio (Albaek et al., 2011).

Devido à necessidade de aeração do meio, os aspersores de gás são utilizados para injetar ar e outros gases no cultivo (Alves, 2010). Os impelidores, por sua vez, promovem a homogeneidade do fluido, evitando a ocorrência de zonas estagnadas, além de serem responsáveis pela formação de correntes de fluxo distintas relacionadas ao tipo utilizado.

Em vista disso, neste trabalho foi avaliado o emprego de biorreatores de agitação mecânica e airlift, com diferentes configurações de impelidores (Rushton e pitched blade) e aspersores de gás (pedra de vidro sinterizado e ferradura) sobre o crescimento de Aspergillus oryzae.

\section{MATERIAL E MÉTODOS}

\subsection{Microrganismo e meio de cultura}

O microrganismo utilizado nos ensaios de crescimento microbiano foi A. oryzae IPT-301 (Fontana et al., 2009; Fontana; Silveira, 2012; Meneghel, 2013), cedido pelo Instituto de Pesquisas Tecnológicas de São Paulo, São Paulo. Para a conservação e a propagação do microrganismo foi utilizado o meio de cultura descrito por Maiorano (1982), com a seguinte composição, em g/L: glicose, 25; glicerina, 25; extrato de levedura, 5 e agar-agar, 20.

O meio de cultivo descrito por Meneghel (2013), isento de pectina, continha (g/L): farelo de trigo em extrato aquoso (Moinho Nordeste, Antônio Prado, Brasil), 40; glicose, 5; extrato de levedura, 0,05; $\left(\mathrm{NH}_{4}\right)_{2} \mathrm{SO}_{4}, 5 ; \mathrm{MgSO}_{4} .7 \mathrm{H}_{2} \mathrm{O}, 0,5 ; \mathrm{KH}_{2} \mathrm{PO}_{4}, 2,5 ; \mathrm{FeSO}_{4} .7 \mathrm{H}_{2} \mathrm{O}, 6,3.10^{-4} ; \mathrm{ZnSO}_{4}$, $6,2.10^{-4} \mathrm{e} \mathrm{MnSO}_{4}, 1.10^{-5}$. O meio foi esterilizado por 10 minutos, a $1 \mathrm{~atm}$. A inoculação feita proporcionou uma concentração final de $10^{5}$ esporos por mililitro de cultura.

\subsection{Condições de cultivo}

Os ensaios foram realizados em dois tipos de equipamentos: um biorreator de agitação mecânica STR (stirred tank reactor), modelo BIOSTAT B (B. Braun Biotech, Sartorius), e um airlift de circulação interna, ambos de 5L de volume total e com volumes de trabalho de 3,5 e 4,5L, respectivamente (Figura 1).

$\mathrm{O}$ pH foi controlado em 4,0( $\pm 0,1)$ com a adição de ácido clorídrico $(\mathrm{HCl}) 2 \mathrm{~mol} / \mathrm{L}$ e hidróxido de sódio $(\mathrm{NaOH}) 2,5 \mathrm{~mol} / \mathrm{L}$. Esse valor foi mantido constante devido ao favorecimento do crescimento microbiano (Malvessi; Silveira, 2004; Meneghel, 2013). O controle da temperatura foi feito por banho termostático a $28( \pm 1,0)^{\circ} \mathrm{C}$.

Em STR, foram testadas três configurações de impelidores e aspersores de gás: a) três impelidores de pás retas inclinadas a $45^{\circ}$ tipo pitched blade (PB), de $62 \mathrm{~mm}$ de diâmetro, distanciados entre si (D) em 4,5cm e aspersor de gás do tipo pedra de vidro sinterizado (PS); b) três $\mathrm{PB}, \mathrm{D}=4,5 \mathrm{~cm}$ e aspersor de gás do tipo ferradura de aço inoxidável (F) e c) três impelidores de pás retas tipo Rushton $(\mathrm{R})$, de $62 \mathrm{~mm}$ de diâmetro, $\mathrm{D}=4,5 \mathrm{~cm}$ e aspersor de gás do tipo PS. Em airlift, foi avaliado o emprego do aspersor do tipo PS. O tubo interno do airlift foi construído em 
vidro refratário, de $5 \mathrm{~cm}$ de diâmetro e $33,5 \mathrm{~cm}$ de altura, e alocado desde a altura do início do aspersor. Os impelidores e os aspersores de gás utilizados nos cultivos são mostrados na Figura 2.

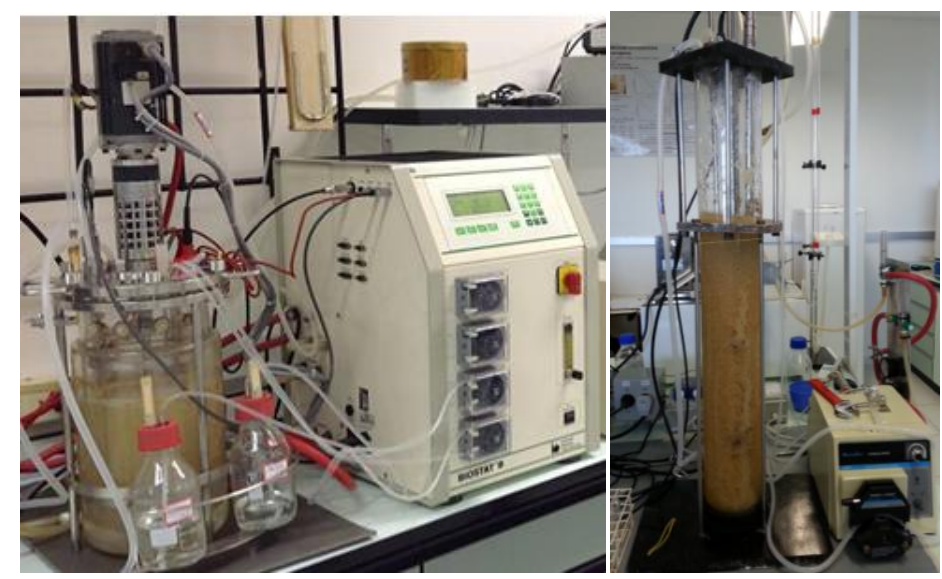

Figura 1 - Biorreatores de agitação mecânica (esquerda) e airlift (direita).

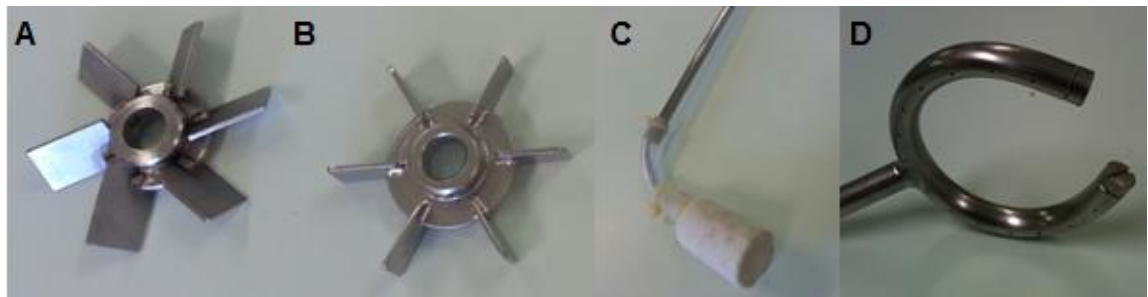

Figura 2 - Impelidores e aspersores de gás utilizados nos cultivos de Aspergillus oryzae em biorreatores de agitação mecânica e airlift.

A: impelidor de pás retas inclinadas a $45^{\circ}$ tipo pitched blade; B: impelidor de pás retas tipo Rushton; C: aspersor de gás do tipo pedra de vidro sinterizado e D: aspersor de gás do tipo ferradura em aço inoxidável.

\subsection{Métodos analíticos}

A determinação da concentração celular foi realizada por gravimetria.

Os açúcares redutores solúveis foram analisados pelo método do ácido 3,5 di-nitro-salicílico (DNS) (Miller, 1959). Os açúcares redutores totais foram determinados através de hidrólise ácida e posterior quantificação das amostras hidrolisadas (Meneghel, 2013) pelo método DNS.

A concentração de oxigênio dissolvido no meio de cultura foi medida com uma sonda polarográfica. A estimativa da concentração de gás foi determinada através da metodologia proposta por Schumpe e Quicker (1982), levando em consideração a concentração dos componentes iônicos e não-iônicos do meio, a retirada das amostras e a adição de ácido e de base para o controle do $\mathrm{pH}$. 


\section{RESULTADOS E DISCUSSÃO}

Os resultados obtidos nos cultivos de A. oryzae em biorreator STR e em biorreator airlift são apresentados na Tabela 1. Nas condições (a) e (b), em que foram utilizados os mesmos tipos de impelidores (pitched blade), valores semelhantes de máximo crescimento microbiano foram obtidos $(5,55 \mathrm{~g} / \mathrm{L}$ e $5,23 \mathrm{~g} / \mathrm{L}$, respectivamente). Porém, em (a), devido ao tipo de aspersor (PS), as condições de mistura e transferência de massa foram facilitadas durante a fase de crescimento exponencial (entre 14 e 25 horas de cultivo). A concentração do oxigênio no meio de cultivo, nessa fase, atingiu valores superiores - em média 6,85 $\mathrm{mgO}_{2} / \mathrm{L}$ (Figura 3). Michelin et at. (2013) destacam que o consumo de oxigênio tende a aproximar-se da velocidade de transferência do gás na fase de crescimento exponencial e, dessa maneira, o percentual de oxigênio dissolvido no meio tende a diminuir, fato que também pode ser observado na Figura 3, independentemente da condição testada.

Tabela 1 - Grandezas de transformação obtidas de cultivo de Aspergillus oryzae em biorreatores de agitação mecânica e airlift

\begin{tabular}{|c|c|c|c|c|}
\hline \multirow{2}{*}{ Parâmetros } & \multicolumn{3}{|c|}{ Agitação mecânica } & \multirow{2}{*}{ airlift } \\
\hline & (a) & (b) & (c) & \\
\hline$X_{\text {máx }}[g / L]$ & 5,55 & 5,23 & 6,34 & 3,55 \\
\hline $\mathbf{t}_{\mathbf{X}, \max }[\mathrm{h}]$ & 28 & 31,5 & 24 & 28,5 \\
\hline dX/dt máx $[g / L / h]$ & 0,41 & 0,54 & 0,40 & 0,33 \\
\hline $\mathbf{t}_{\mathbf{d X} / \mathbf{d t}, \mathbf{m a ́ x}}[\mathbf{h}]$ & 18,3 & 19 & 17,6 & 22,5 \\
\hline $\mathbf{d S} / \mathbf{d t}_{\text {máx }}[\mathrm{g} / \mathbf{L} / \mathbf{h}]$ & 1,13 & 0,84 & 1,66 & 1,75 \\
\hline $\mathbf{t}_{\text {dS/dt,máx }}[\mathbf{h}]$ & 20,8 & 20,7 & 20,3 & 23,3 \\
\hline$\mu_{\mathrm{x}, \text { máx }}\left[\mathrm{h}^{-1}\right]$ & 0,19 & 0,22 & 0,14 & 0,17 \\
\hline $\mathbf{t}_{\mu x, \operatorname{máx}}[\mathrm{h}]$ & 13,6 & 17,8 & 15 & 21,7 \\
\hline $\boldsymbol{\mu}_{\mathrm{s}, \text { máx }}\left[\mathbf{h}^{-1}\right]$ & 0,32 & 0,27 & 0,38 & 0,75 \\
\hline $\mathbf{t}_{\mu \mathrm{s}, \text { máx }}[\mathbf{h}]$ & 19,8 & 19,4 & 20,3 & 22,7 \\
\hline
\end{tabular}

Condições: (a) três impelidores de pás retas inclinadas a $45^{\circ}$ tipo pitched blade (PB), distanciados entre si (D) em 4,5cm e aspersor de gás do tipo pedra de vidro sinterizado (PS); (b) três $\mathrm{PB}, \mathrm{D}=4,5 \mathrm{~cm}$ e aspersor de gás do tipo ferradura em aço inoxidável (F) e (c) três impelidores de pás retas tipo Rushton $(\mathrm{R})$, de $62 \mathrm{~mm}$ de diâmetro, $\mathrm{D}=4,5 \mathrm{~cm}$ e aspersor de gás do tipo PS. $\mathrm{X}_{\text {máx }}$ : máxima concentração de biomassa; $\mathrm{t}_{\mathrm{X}, \text { máx }}$ : tempo para atingir a máxima concentração de biomassa; $\mathrm{dX} / \mathrm{dt}_{\text {máx }}$ : máxima velocidade instantânea de crescimento; $\mathrm{t}_{\mathrm{dX} / \mathrm{d} \text { t,máx }}$ : tempo para atingir a máxima velocidade instantânea de crescimento; $\mathrm{dS} / \mathrm{dt}_{\text {máx }}$ : máxima velocidade instantânea de consumo de substrato; $\mathrm{t}_{\mathrm{dS} / \mathrm{d} \text { t,máx }}$ : tempo para atingir a máxima velocidade instantânea de consumo de substrato; $\mu_{\mathrm{x}, \text { máx }}$ : máxima velocidade específica de crescimento celular; $\mathrm{t}_{\mu \mathrm{x} \text {,máx }}$ : tempo para atingir a máxima velocidade específica de crescimento celular; $\mu_{\mathrm{s}, \text { máx }}$ : máxima velocidade específica de consumo de substrato; $\mathrm{t}_{\mu \mathrm{s}, \text { máx }}$ : tempo para atingir a máxima velocidade específica de consumo de substrato.

Na condição (b), em que foi utilizado um aspersor de gás do tipo ferradura $(\mathrm{F})$, foi calculado o maior valor para velocidade específica de crescimento máxima $\left(\mu_{\mathrm{x}, \text { máx }}=0,22 \mathrm{~h}^{-1}\right)$, porém em tempo de cultivo mais longo (17,8h) em relação às condições (a) e (c), 13,6h e 15h, respectivamente. $\mathrm{O}$ maior tempo necessário para atingir $\mu_{\mathrm{x}, \mathrm{máx}}$ foi, possivelmente, devido à influência do maior tamanho de bolhas formadas pelo aspersor tipo ferradura, quando comparado com o aspersor de vidro sinterizado, como pode ser observado na Figura 4. Rocha-Valadez et al. (2000) avaliaram o efeito da combinação entre o aspersor de gás e o impelidor no crescimento de Trichoderma harzianum. Os autores mostraram que a utilização de aspersores de gás com 
tamanhos de orifícios maiores, e consequente formação de bolhas de gás de diâmetros superiores, levaram à redução da área interfacial, do hold-up e do $\mathrm{k}_{\mathrm{L}} \mathrm{a}$, parâmetros relacionados com a transferência de massa gás-líquido.

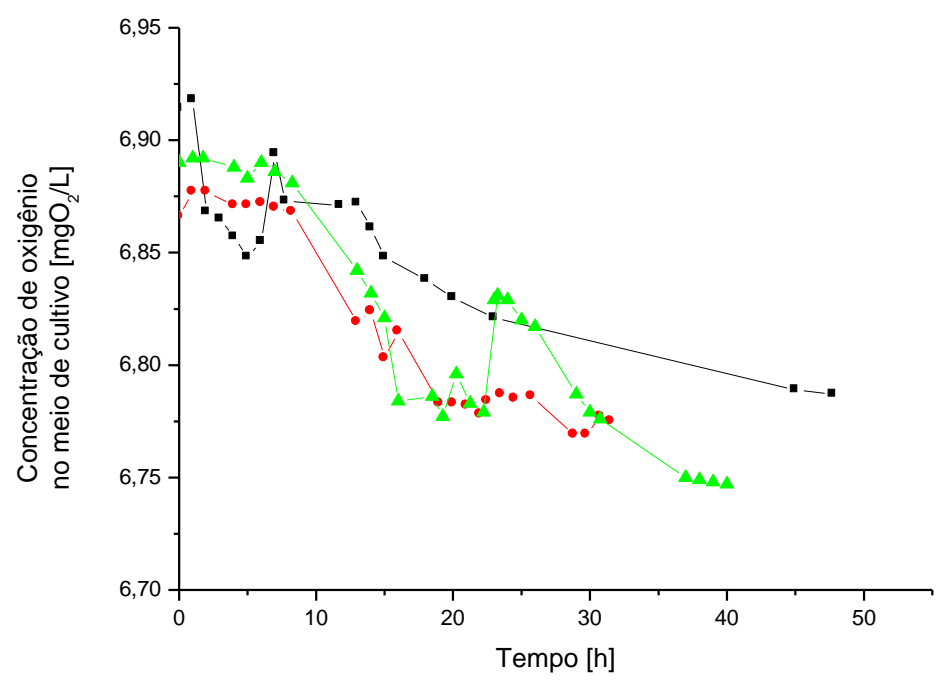

Figura 3 - Concentração de oxigênio no meio de cultivo de Aspergillus oryzae em função do tempo, em biorreator de agitação mecânica.

Condições: a ( ') três impelidores de pás retas inclinadas a $45^{\circ}$ tipo pitched blade (PB), distanciados (D) em 4,5cm e aspersor de gás do tipo pedra de vidro sinterizado (PS); $\mathbf{b}(\bullet)$ três $\mathrm{PB}, \mathrm{D}=4,5 \mathrm{~cm}$ e aspersor de gás do tipo ferradura em aço inoxidável (F); c ( $\ldots$ ) três impelidores de pás retas tipo Rushton $(\mathrm{R})$, de $62 \mathrm{~mm}$ de diâmetro, $\mathrm{D}=4,5 \mathrm{~cm}$ e aspersor de gás do tipo PS.

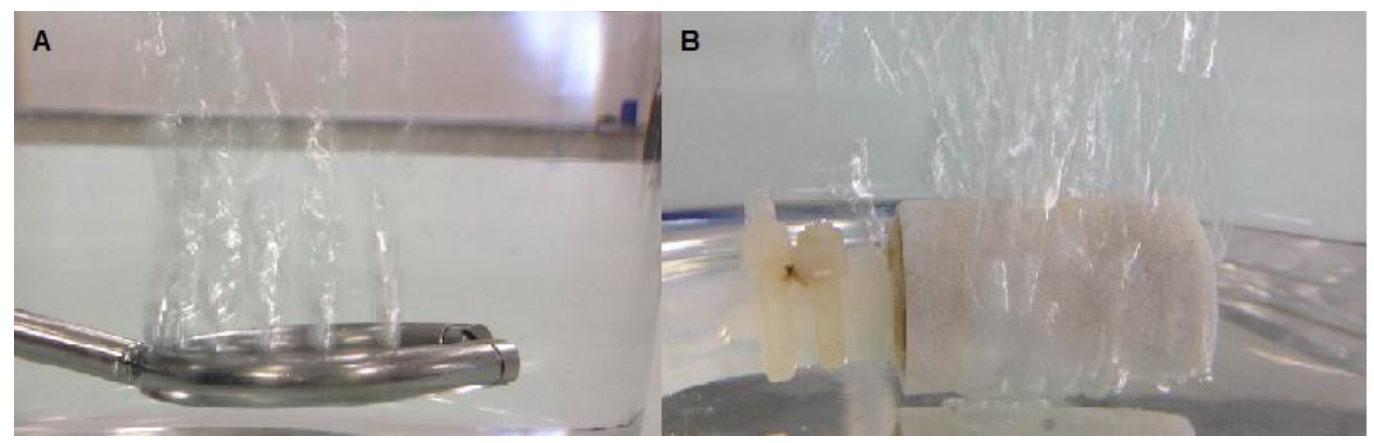

Figura 4 - Bolhas de gás formadas quando utilizados aspersores do tipo (A) ferradura em aço inoxidável e (B) pedra de vidro sinterizado.

Na condição (c), foi obtido valor superior de biomassa $(6,34 \mathrm{~g} / \mathrm{L})$ em menor tempo de cultivo (24h). Isso pode estar relacionado com o tipo de impelidor utilizado (Rushton), o qual gera correntes de fluxo primordialmente na direção radial (Queiroz, 2009), possivelmente acarretando no baixo cisalhamento fúngico e, consequentemente, no maior valor de crescimento microbiano. Sardeing et al. (2004) destacam que a energia dissipada por impelidores do tipo Rushton é utilizada para a quebra das bolhas de gás. Com isso, tem-se o aumento de $a$ (área interfacial de transferência de massa por volume total de líquido) e, consequentemente, o aumento da turbulência próximo à interface entre o gás e o líquido, o que resulta no aumento de $k_{L}$ (coeficiente 
de transferência de massa da película líquida). Nessa mesma condição testada, foi obtida a maior velocidade máxima de consumo de substrato $\left(\mu_{\mathrm{s}, \operatorname{máx}}=0,38 \mathrm{~h}^{-1}\right)$ (Tabela 1$)$, podendo estar relacionado com o tipo de aspersor de gás utilizado (pedra de vidro sinterizado), o qual gera bolhas de gás menores, aumentando a área superficial de contato entre o gás e o microrganismo. Assim, auxilia nos processos de transferência de massa e de obtenção de biomassa e, consequentemente, acelera o processo de consumo de carboidratos.

Comparando-se os resultados nas condições de processo em STR e em airlift (Tabela 1), o crescimento microbiano obtido em airlift, além de mais baixo $(3,55 \mathrm{~g} / \mathrm{L})$, foi obtido em tempo mais longo de cultivo em relação a qualquer outra condição avaliada. Isso provavelmente está relacionado ao sistema de agitação pneumático do airlift. Nesse sistema, o crescimento microbiano na forma de pellets (Figura 5) dificulta o contato gás-microrganismo e a transferência de gás para as hifas mais internas. Com a formação de pellets, há aumento da coalescência das bolhas e, consequentemente, a limitação no transporte de massa. Já em STR, devido à presença de impelidores que fazem a ruptura das células, não é visível a formação de pellets (Rodríguez Porcel et al., 2005).

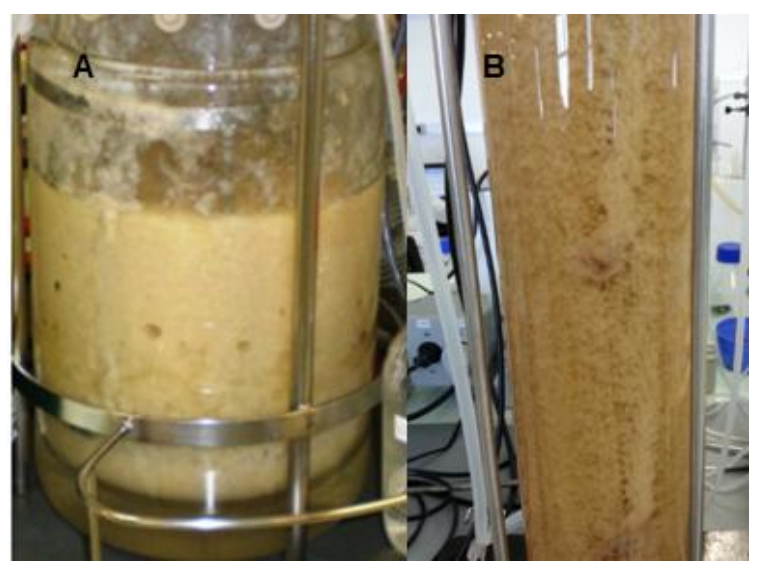

Figura 5 - Crescimento microbiano em cultivo de Aspergillus oryzae em biorreator de agitação mecânica (A) e airlift (B).

Apesar dos resultados inferiores de crescimento de $A$. oryzae obtidos na condição experimental testada em airlift, vale ressaltar a importância de sua utilização em scale-up (aumento de escala), seu potencial uso em termos de sustentabilidade e na produção de, por exemplo, lacases (Liu et al., 2013), celulases (Ahamed; Vermette, 2010) e outras enzimas de interesse.

\section{CONCLUSÕES}

Os resultados apresentados evidenciaram a importância de uma correta escolha do tipo de biorreator e sua engenharia em processos envolvendo cultivos fúngicos para obtenção de biomassa. Os cultivos conduzidos em ambos os reatores biológicos mostraram que, apesar da obtenção de resultados distintos, são indicados para a condução de processos com microrganismos aeróbios. Embora preliminares, esses resultados de crescimento microbiano, aliados à reologia do sistema, são de suma importância em termos de avaliação posterior de produção de complexos 
enzimáticos pectinolíticos por A. oryzae.

\section{AGRADECIMENTOS}

Os autores agradecem a Universidade de Caxias do Sul (UCS) pela infraestrutura cedida para a realização deste trabalho, ao apoio da Coordenação de Aperfeiçoamento de Pessoal de Nível Superior (CAPES) e do Conselho Nacional de Desenvolvimento Científico e Tecnológico $(\mathrm{CNPq})$ e a Fundação de Amparo à Pesquisa do Estado do Rio Grande do Sul (FAPERGS) pelo suporte financeiro.

\section{REFERÊNCIAS}

AHAMED, A.; VERMETTE, P. Effect of mechanical agitation on the production of cellulases by Trichoderma reesei RUT-C30 in a draft-tube airlift bioreactor. Biochem. Eng. J., v. 49, p. 379-387, 2010.

ALBAEK, M.O.; GERNAEY, K.V.; HANSEN, M.S.; STOCKS, S.M. Modeling enzyme production with Aspergillus oryzae in pilot scale vessels with different agitation, aeration, and agitator types. Biotechnol. Bioeng., v. 108, n. 8, 2011.

ALVES, F. Modelagem e simulação de biorreator operando com fungos Trametes versicolor para produção de enzima lacase. Dissertação (Mestrado em Engenharia de Processos Químicos e Bioquímicos)-Escola de Engenharia Mauá, São Caetano do Sul, São Paulo, 2010.

FONTANA, R.C.; SILVEIRA, M.M. Production of polygalacturonases by Aspergillus oryzae in stirred tank and internal- and external-loop airlift reactors. Bioresour. Technol., v. 123, p. 157-163, 2012.

FONTANA, R.C.; POLIDORO, T. A.; SILVEIRA, M.M. Comparison of stirred tank and airlift bioreactors in the production of polygalacturonases by Aspergillus oryzae. Biores. Technol., v. 100, p. 4493-4498, 2009.

GÓMEZ SÁNCHEZ, C. E.; MARTÍNEZ-TRUJILlO, A.; AGUILAR OSORIO, G. Oxygen transfer coefficient and the kinetic parameters of exo-polygalacturonase production by Aspergillus flavipes FP-500 in shake flasks and bioreactor. Lett. Appl. Microbiol., v. 55, p. 444-452, 2012.

JAYANI, R.S., SAXENA, S.; GUPTA, R. Microbial pectinolytic enzymes: A review. Process Biochem., v. 40, p. 2931-2944, 2005.

LIU, J.; CAI, Y.; LIAO, X.; HUANG, Q.; HAO, Z.; HU, M.; ZHANG, D.; LI, Z. Efficiency of laccase production in a $65-\mathrm{L}$ air-lift reactor for potential green industrial and environmental application. J. Cleaner Prod., v. 39, p. 154-160, 2013.

MAIORANO, A.E. Influência da concentração de inóculo e da temperatura na produção de enzimas amilolíticas por cultivo de Aspergillus oryzae em meio semi-sólido. Dissertação (Mestrado). Escola Politécnica, Universidade de São Paulo, SP, 1982.

MALVESSI, E.; SILVEIRA, M. M. Influence of medium composition and $\mathrm{pH}$ on the production of polygalacturonases by Aspergillus oryzae. Braz. Arch. Biol. Technol., v. 47, p. 693-702, 2004.

MENEGHEL, L. Avaliação da produção de pectinases por Aspergillus oryzae IPT-301 em 
processo submerso. Dissertação (Mestrado). Programa de Pós-Graduação em Biotecnologia, Universidade de Caxias do Sul, RS, 2013.

MICHELIN, M.; DE OLIVEIRA MOTA, A. M.; TEIXEIRA DE MORAES POLIZELI, M. L.; PEREIRA DA SILVA, D.; VICENTE, A. A.; TEIXEIRA, J. A. Influence of volumetric oxygen transfer coefficient $\left(\mathrm{k}_{\mathrm{L}} \mathrm{a}\right)$ on xylanases batch production by Aspergillus niger van Tieghem in stirred tank and internal-loop airlift bioreactors. Biochem. Eng. J., v. 80, p. 1926, 2013.

MILLER, G. L. Use of dinitrosalicylic acid reagent for determination of reducing sugar. Anal. Chem., v. 31, p. 426, 1959.

NAJAFPOUR, G. D. 2007. Bioreactor Design. In: NAJAFPOUR, G. D. Biochemical Engineering and Biotechnology. Elsevier, pp. 142-169.

QUEIROZ, R. B. A influência do acabamento da superfície interna do tanque no número de potência de novos impelidores. 2009. 65 f. Dissertação (Mestrado em Engenharia Mecânica)-Faculdade de Engenharia de Bauru da UNESP, Universidade Estadual Paulista Júlio de Mesquita Filho, Bauru, 2009.

REZAZADEH BARI, M.; ALIZADEH, M.; FARBEH, F. Optimizing endopectinase production from date pomace by Aspergillus niger PC5 using response surface methodology. Food Bioprod.Process., v. 88, p. 67-72, 2010.

ROCHA-VALADEZ, J.A.; GALINDO, E.; SERRANO-CARREÓN, L. Effect of the impellersparger configuration over Trichoderma harzianum growth in four-phases cultures under constant dissolved oxygen. Bioprocess Eng. v. 23, p. 403-410, 2000.

RODRÍGUEZ PORCEL, E.M.; CASA LÓPEZ, J.L.; SÁNCHEZ PÉREZ, J.A.; FERNÁNDEZ SEVILLA, J.M.; CHISTI, Y. Effect of pellet morphology on broth rheology in fermentations of Aspergillus terreus. Biochem. Eng. J. v. 26, p. 139-144, 2005.

SARDEING, R.; AUBIN, J.; XUEREB, C. Gas-liquid mass transfer: A comparison of down- and up-pumping axial flow impellers with radial impellers. Chem. Eng. Res. Des., v. 82, p. 15891596, 2004.

SCARGIALI, F.; BUSCIGLIO, A.; GRISAFI, F.; BRUCATO, A. Mass transfer and hydrodynamic characteristics of unbaffled stirred bio-reactors: Influence of impeller design. Biochem. Eng. J., v. 82, p. 41-47, 2014.

SCHUMPE A.; QUICKER, G. Gas solubilities in microbial culture media. In: Adv. Biochem. Eng., Berlin: Springer-Verlag, Ghose TK, Fiechter A and Blakebrough N., v. 24, p 1-37, 1982. 